This item was submitted to Loughborough's Research Repository by the author.

Items in Figshare are protected by copyright, with all rights reserved, unless otherwise indicated.

\title{
On the mechanism of controlled auto ignition
}

PLEASE CITE THE PUBLISHED VERSION

http://www.sae.org/congress/2002/

PUBLISHER

(c) SAE International

VERSION

VoR (Version of Record)

LICENCE

CC BY-NC-ND 4.0

REPOSITORY RECORD

Law, Don, Jeff Allen, and Rui Chen. 2011. "On the Mechanism of Controlled Auto Ignition”. figshare. https://hdl.handle.net/2134/8402. 
This item was submitted to Loughborough's Institutional Repository (https://dspace.lboro.ac.uk/) by the author and is made available under the following Creative Commons Licence conditions.

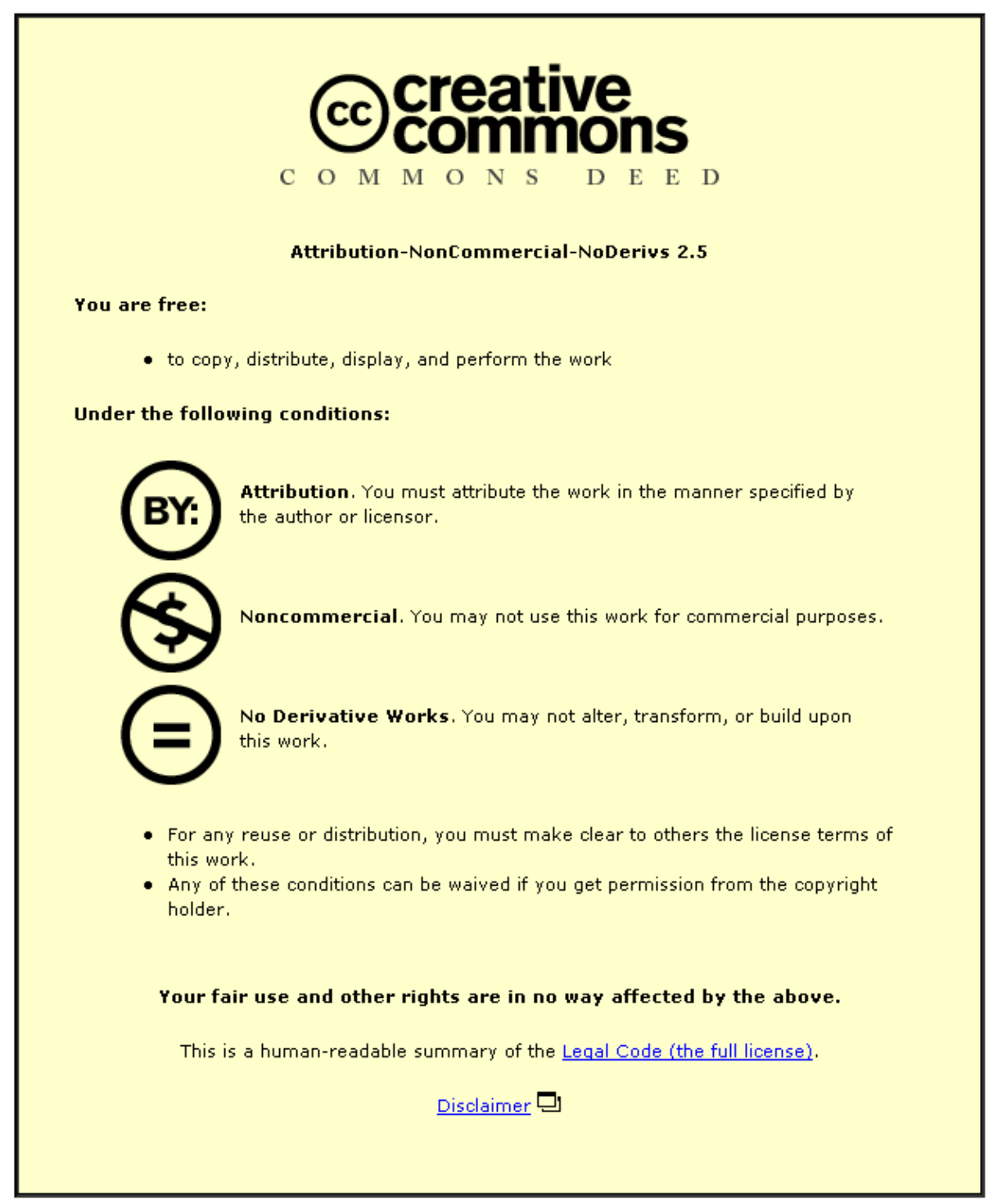

For the full text of this licence, please go to: http://creativecommons.org/licenses/by-nc-nd/2.5/ 


\section{On the Mechanism of Controlled Auto Ignition}

Don Law and Jeff Allen

Lotus Engineering

Rui Chen

Dept. of Aeronautical \& Automotive Engrg., Loughborough Univ.

Reprinted From: Homogeneous Charge Compression Ignition (HCCl) Combustion 2002

(SP-1688) 
The appearance of this ISSN code at the bottom of this page indicates SAE'S consent that copies of the paper may be made for personal or internal use of specific clients. This consent is given on the condition, however, that the copier pay a per article copy fee through the Copyright Clearance Center, Inc. Operations Center, 222 Rosewood Drive, Danvers, MA 01923 for copying beyond that permitted by Sections 107 or 108 of the U.S. Copyright Law. This consent does not extend to other kinds of copying such as copying for general distribution, for advertising or promotional purposes, for creating new collective works, or for resale.

Quantity reprint rates can be obtained from the Customer Sales and Satisfaction Department.

To request permission to reprint a technical paper or permission to use copyrighted SAE publications in other works, contact the SAE Publications Group.

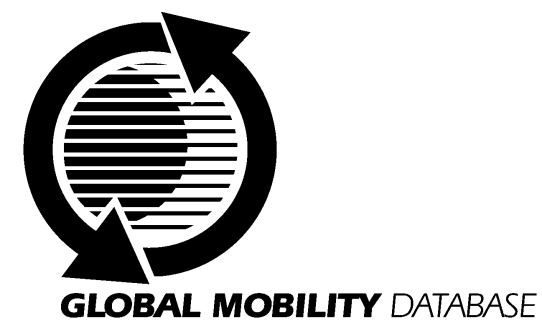

All SAE papers, standards, and selected books are abstracted and indexed in the Global Mobility Database

No part of this publication may be reproduced in any form, in an electronic retrieval system or otherwise, without the prior written permission of the publisher.

\section{ISSN 0148-7191}

Copyright $\odot 2002$ Society of Automotive Engineers, Inc.

Positions and opinions advanced in this paper are those of the author(s) and not necessarily those of SAE. The author is solely responsible for the content of the paper. A process is available by which discussions will be printed with the paper if it is published in SAE Transactions. For permission to publish this paper in full or in part, contact the SAE Publications Group.

Persons wishing to submit papers to be considered for presentation or publication through SAE should send the manuscript or a 300 word abstract of a proposed manuscript to: Secretary, Engineering Meetings Board, SAE.

\section{Printed in USA}




\title{
On the Mechanism of Controlled Auto Ignition
}

\author{
Don Law and Jeff Allen
}

Lotus Engineering

Rui Chen

Dept. of Aeronautical \& Automotive Engrg., Loughborough Univ.

Copyright (C 2002 Society of Automotive Engineers, Inc.

\begin{abstract}
Controlled auto ignition (CAI) is a form of combustion which uses an auto-ignited homogeneous air/fuel mixture but is controlled (or moderated) by regulating the quantity of internal exhaust gas residuals. In this paper, using a fully variable valve train and a newly developed exhaust valve control strategy, we substituted EGR with hot nitrogen or hot air. We found that the internal exhaust gas residuals have both thermal and chemical effects on CAI combustion. To investigate the thermal effect, nitrogen was used as it is a chemically inert gas. Although its temperature was raised to that of the internal exhaust gas residuals during testing, CAI combustion could not be promoted without assistance from a spark in a form of hybrid CAl, thus indicating that exhaust gas residuals have a chemical effect as well. Conversely, with the introduction of oxygen (which in air is a reactant of combustion), no auto ignition combustion occurred until its temperature was increased to $120^{\circ} \mathrm{C}$, proving that a minimum thermal condition of an added gas is required to generate auto-ignition. Comparing this EGR introduction, we found that nitrogen has the ability to delay combustion and smooth the pressure increase rate, while oxygen accelerates combustion and turns CAI combustion into an uncontrollable form normally associated with knock. These effects help to explain the contribution of the chemical effect of the EGR on CAI combustion since exhaust gas residuals contain nitrogen as well as chemically active species.
\end{abstract}

\section{INTRODUCTION}

Controlled auto-ignition (CAI) in an internal combustion engine fuelled with gasoline is a combustion phenomenon which uses auto-ignited homogeneous air and fuel charge, the combustion being controlled by regulating the quantity of internal exhaust gas recirculation (EGR). It offers considerable benefits in fuel economy and reduced emissions potential. Controlled auto ignition is still a distance away from practical application due to lack of knowledge into the mechanism of such combustion. Such combustion has grown in interest in recent years originally arising from work on 2stroke engines [1-10], and has now crossed to 4-stroke engines [11-18]. The reason for the interest in 4-stroke engines stems from the fact that CAI combustion holds considerable promise as a part-load throttle-less engine control strategy which is capable of yielding superior fuel economy and significantly reduced pollutants $[19,20]$. It has been proved through our previous research results that such a combustion phenomenon can be practically controlled in a certain engine operation range by controlling the quantity of re-circulated engine exhaust gas, EGR, using an advanced active valve train (AVT) system $[21,22]$.

Two exhaust valve control strategies have been successfully established in sustaining CAI combustion in a single cylinder research engine [17]. Strategy one relies on trapping a pre-determined quantity of exhaust gasses by closing exhaust valves relatively early in the exhaust stroke. In strategy two, as the piston reaches BDC from the power stroke, the exhaust valves are opened and all of the exhaust gas is expelled from the cylinder. As the piston commences the next induction stroke, both inlet and exhaust valves are opened simultaneously and both fresh charge and exhaust gas are drawn simultaneously into the cylinder. Once inlet and exhaust valves have closed, the piston begins to compress the mixture of fresh charge and trapped exhaust gas. There is a common feature of the two control strategies, which is the fact that the mixing between EGR and fuel/air fresh charge happens inside the combustion chamber. Hence, both of these two strategies can be regarded as internal EGR mixing process. Using these strategies, the EGR has little or no time to contact cooler surfaces. Therefore, its temperature remains high. Exiting exhaust gas temperature using both methods of promoting CAI, as measured with a thermocouple immediately behind an exhaust valve, is typically $350-400^{\circ} \mathrm{C}$.

There is a third method to introduce the engine's EGR back into air/fuel fresh charge, which is to redraw the 
expelled exhaust gas back into the engine's inlet manifold. By doing so, the EGR will pre-mix with the air/fuel fresh charge before being introduced into the combustion chamber. Hence, this third method should be regarded as an external EGR mixing process.

Through our research, we have found that the first two different EGR mixing processes have distinct effects on initiating CAl combustion. In our early attempts to initiate CAI, external EGR mixing processes were used. High temperatures, between $150-200^{\circ} \mathrm{C}$, in routing EGR gas from the exhaust pipe around to the intake manifold were maintained. Although the volumes of the EGR were ramped up to approximately $70 \%$ of the engine cylinder volume, we found that the engine were unable to run in a true spark-less mode, which is the characteristic of CAl. In comparison, CAl can be promoted with an internal EGR mixing process as low as $36 \%$ of the engine cylinder volume.

If external EGR mixing processes at temperatures as high as $200^{\circ} \mathrm{C}$ do not promote CAl, but internal EGR does, then why? Researchers have attempted to resolve this problem and valuable details have surfaced. However, great debate still ensues regarding the possible mechanism of CAI combustion and the key to initiating such combustion, such as the effect of chemical species contained in the exhaust gas residuals, their molecular form and reactivity, and, typically, the debate over how pressure, temperature and chemical species influence CAI combustion [23-31].

In order to clarify the question of the effect of EGR on the mechanism of CAI, and to provide a potential platform for further development of CAI combustion into a practical engine control strategy, we performed a series of experimental investigations. The results obtained from this work have been analysed and are presented in this paper.

\section{MECHANISM OF CAI COMBUSTION}

In a theoretical investigation performed recently [32], we realised that all these debates about the effect of EGR on CAI combustion can actually be reduced to two aspects: thermal effect and chemical effect.

Exhaust gas residuals contribute towards CAI combustion due to their high temperature. When a hot gas is mixed with a cool air-fuel mixture, the hot gas improves the temperature of the entire engine inlet charge, thus increasing the in-cylinder temperature during the compression process and this in turn helps the charge to overcome its activation energy. The chemical effect is due to the contribution of certain chemical species in the exhaust gas residuals on the chemical kinetics of CAI combustion. Different species have different chemical activity towards the combustion reactions. Their presence in the EGR will therefore influence the contribution of EGR towards CAI combustion. The engine exhaust gas contains a large number of different chemical species, some of them have been realised to be very active in combustion reactions for a long time and therefore have a strong chemical effect in promoting CAl combustion.

In our investigation, we substituted EGR firstly with nitrogen and secondly with air. It was found that nitrogen has little effect on ignition timing but has a high impact on combustion heat release rate when nitrogen is heated to a sufficiently high level. Nitrogen is generally a chemically inert gas, and when it is introduced into the engine combustion chamber in a hot state, its main contribution towards combustion is predominantly a thermal effect. The more nitrogen is introduced, the more the charge is diluted and so lower combustion heat release rates are achieved, no matter whether CAI combustion can be maintained or not.

Conversely, oxygen (as air), is part of the reactant of combustion reaction. The experimental results show that oxygen addition advances CAl combustion ignition timing, but with little effect on combustion heat release rate. The advance in ignition timing means that oxygen improves CAl combustion, whilst the relatively small effect on heat release rate may be due to the fact that the combustion is advanced so much. Any dilution effect due to oxygen addition has been compromised by the advanced combustion timing.

\section{EXPERIMENTAL INVESTIGATION}

In order to confirm our understanding we performed a series of experimental studies. In the work, we have deliberately separated thermal and chemical effects of EGR by substituting EGR with pre-heated nitrogen and pre-heated air. The chemical effect is tested with hot nitrogen introduction. The thermal and the chemical effect is monitored with hot air.

\section{AVT Engine}

To experimentally substitute EGR with nitrogen and air and study their effects on CAl combustion, a specially designed engine has been used. The engine is a single cylinder unit fitted with a research grade AVT system together with a specially-partitioned exhaust port.

The engine has a swept volume of $0.45 \mathrm{~L}$. Its architecture, head, port and cylinder are representative of the geometry used in a standard 1.8L 4-cylinder multipoint fuel injection engine in production in Europe today.

The opening and closing timing of each of the four electrohydraulically driven valves are independently variable and can be digitally controlled. Valve opening profiles can be selected and entered into the software by the user; the control software uses inputs from a 
crankcase encoder and valve linear displacement transducers to facilitate a closed-loop control to satisfy a desired versus actual position control until the required profiles are achieved. Fine tuning of valve profiles is accomplished using valve-specific gain controllers.

The exhaust port of the engine has been partitioned into two sub-ports, and connected to each exhaust valve independently. By tuning the timing of two exhaust valves separately, the partitioned exhaust port permits the two exhaust valves to be used either simultaneously or timed differently for different tasks. In this research, when nitrogen and air is used to substitute the EGR, one is timed to expel the exhaust gas and the other is used to intake nitrogen or air.

Figures 1-3 show the details of the engine, and Table 1 gives additional information. In Figure 1, the partitioned exhaust ports can be seen at (a) and (b), where (a) is used for expelling the exhaust and (b) is used for nitrogen or air introduction in this case. (c) is the exhaust pipe. Figure 2 shows the single cylinder engine fitted with the research grade AVT at (a). Again, the hot nitrogen/air feed pipe can be seen at (b) and the exhaust pipe at (c). Finally, in Figure 3, the main heater used to elevate the temperature of the nitrogen or air can be seen at (b) with the exhaust clearly separate at (a).

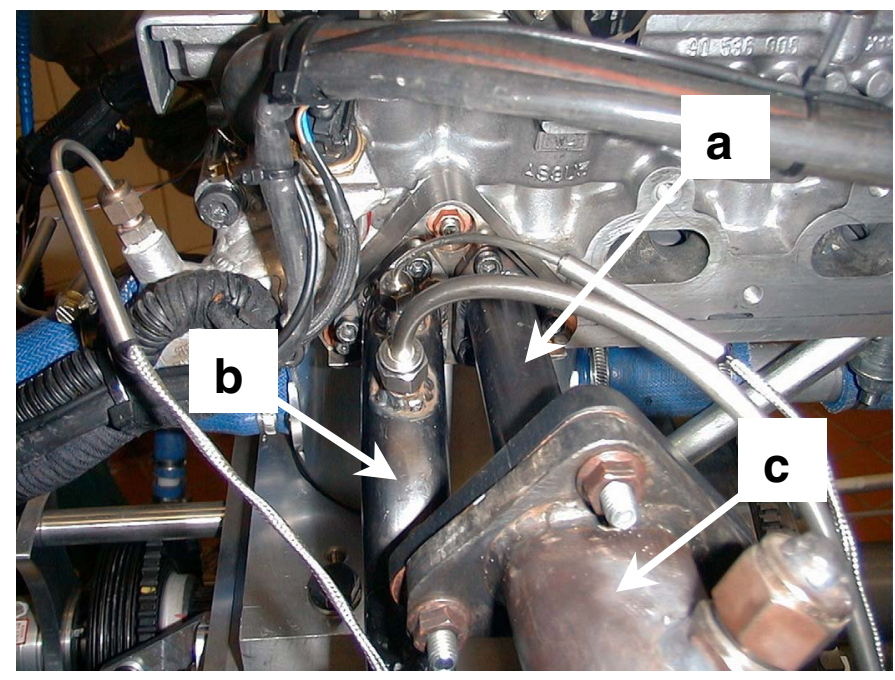

Figure 1 Side view of the engine cylinder head showing the partitioned exhaust port (a) and (b), and the exhaust pipe(c)

Table 1 Single cylinder engine specification

\begin{tabular}{|l|l|}
\hline Bore & $80.5 \mathrm{~mm}$ \\
\hline Stroke & $88.2 \mathrm{~mm}$ \\
\hline Compression Ratio & $10.5: 1$ \\
\hline Max speed & $5000 \mathrm{rpm}$ \\
\hline Number of valves & 4 \\
\hline Fuel Injection & Port Fueled \\
\hline Fuel & Gasoline (95RON) \\
\hline
\end{tabular}

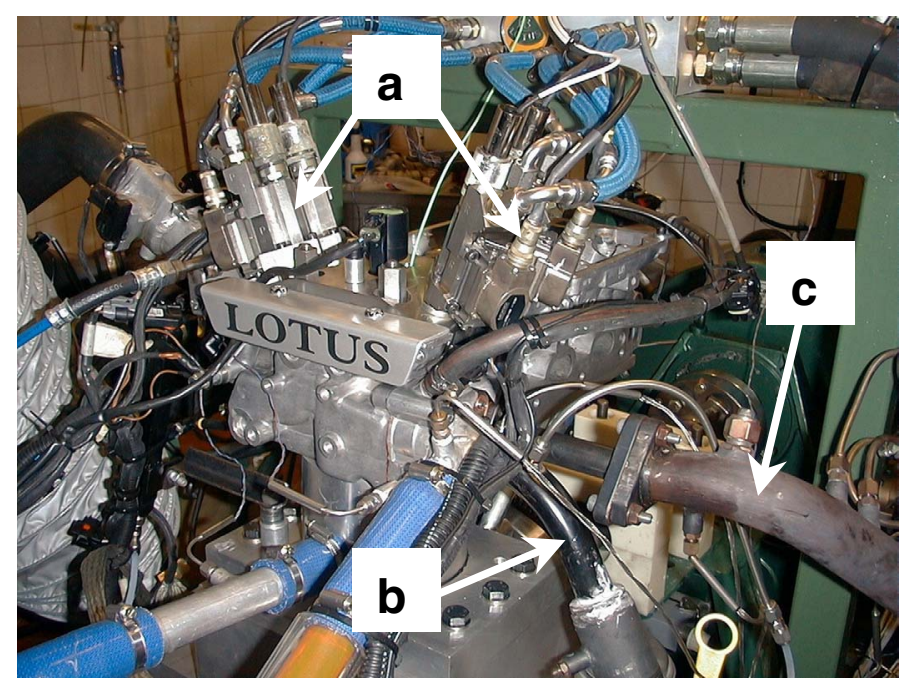

Figure 2 Side view of the engine showing the research grade active valve train (a), the nitrogen or air feeding pipe (b), and exhaust pipe (c)

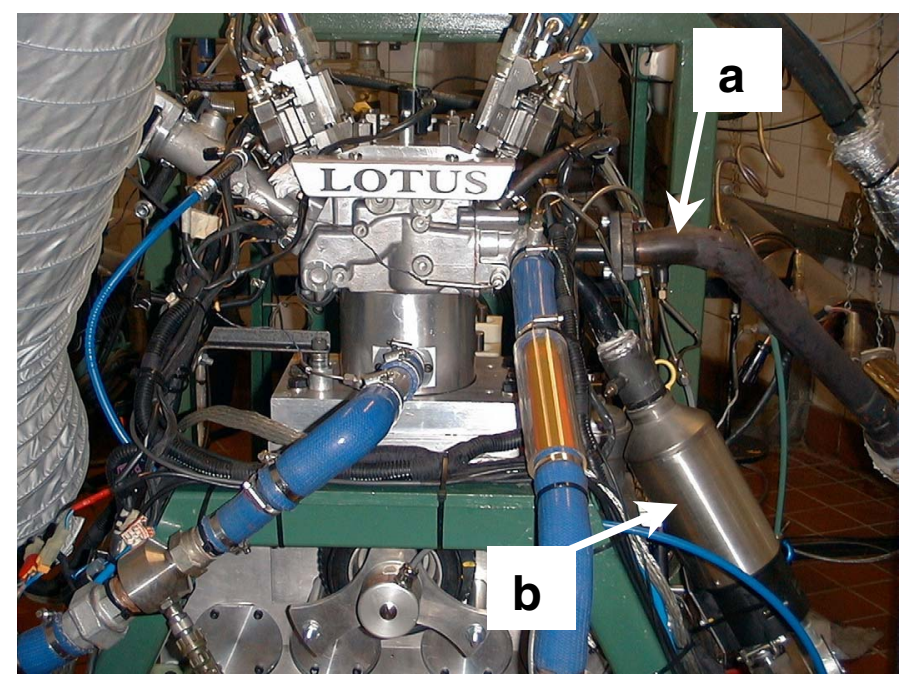

Figure 3 Front view of the engine showing the exhaust pipe (a) and electric heater (b)

\section{Experimental Study on EGR}

The first set of experimental studies on CAI combustion were completed using the second of the two valve control strategies described earlier for promoting CAI combustion with internal EGR. Both exhaust valves were connected to the exhaust pipe and controlled simultaneously. Figure 4, shows the timing for the valves. The engines exhaust gas is initially expelled through the two exhaust valves during the exhaust process and then drawn back into the chamber through the same valves during the following intake process. The engine speed was maintained at 2000rpm. The quantity of the EGR redrawn into the engine depends upon valve timing, and was tuned to approximately $45-50 \%$ of cylinder volume in this study. 

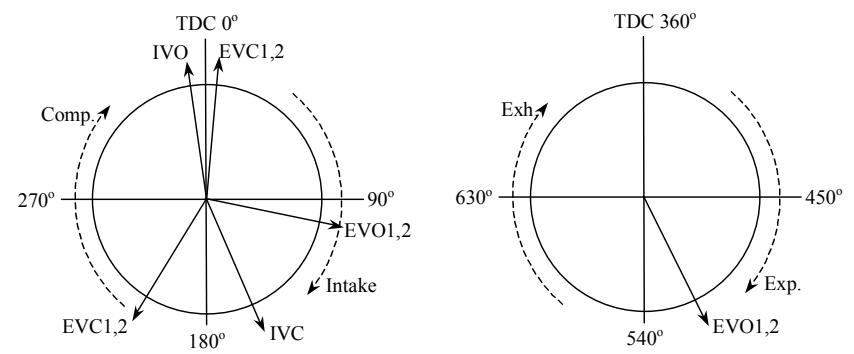

Figure 4 Valve timing for CAI combustion with EGR

Figure 5 shows the measured cylinder pressure data of 100 sequential cycles. Two cylinder pressure increases are apparent, the first one with peak values of approximately 50bar, corresponds to CAI combustion. The second pressure peak, of approximate $4 \mathrm{bar}$, is an artefact of trapped residual gas in-cylinder due to the valve overlap strategy. Clearly, this pressure pulse is completely separated from the main combustion event. It therefore has little if no effect on the main combustion.

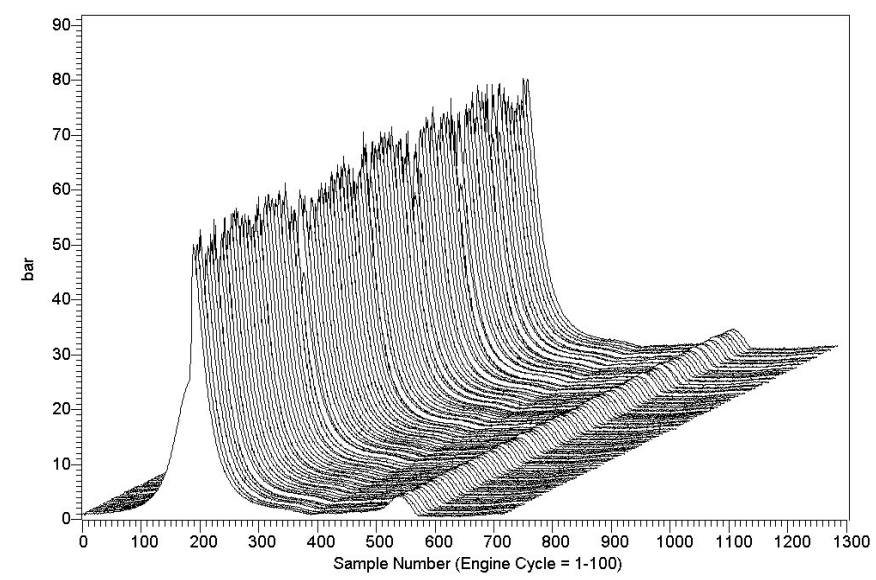

Figure 5 Pressure traces of CAl combustion using two exhaust valves [17].

Following the initial approach, one of the two exhaust valves was deliberately deactivated while the other one opened conventionally using the same strategy as shown in Figure 4. In this case, all the engine's exhaust gas has to be expelled out and redrawn back through a single valve. Due to the increased flow restriction, the EGR drawn back into the cylinder may be slightly less than that using double exhaust valves. All other engine operation conditions remained the same. We found that CAI combustion could still be generated and maintained using one exhaust valve. Figure 6 shows the measured cylinder pressure data.

Comparing both CAI combustion results (Figure 5 and 6 ), it can be seen that the overall pressure signature is similar, peak pressures, in Figure 6, are slightly noisier and pressure rise timings are slightly delayed using the single exhaust valve method of operation. The difference observed in peak pressure noise levels, arises from the fact that, in deactivating one of the two exhaust valves available to draw exhaust gas back into the cylinder, that this restricts in-cylinder fresh charge/residual exhaust gas mixing processes. This then leads to an in-cylinder condition, which is less homogeneous than an engine operating strategy where both exhaust valves are used. Since the mixture is more heterogeneous, the pressure signature becomes noisier. Further experimentation is needed to establish at what level of in-cylinder mixture heterogeneity would not support CAI combustion and what the effect on combustion timing would be.

The slight delay in angle of Pmax may also be due to less EGR having been re-drawn into the cylinder by the single valve strategy. From previous work, less EGR introduction has been shown to delay ignition timing [17]. The key feature of the test shown in Figure 6 is the fact that, despite small differences in the overall combustion event, CAI can also be obtained using a single exhaust valve with the same operating strategy to that with double exhaust valves.

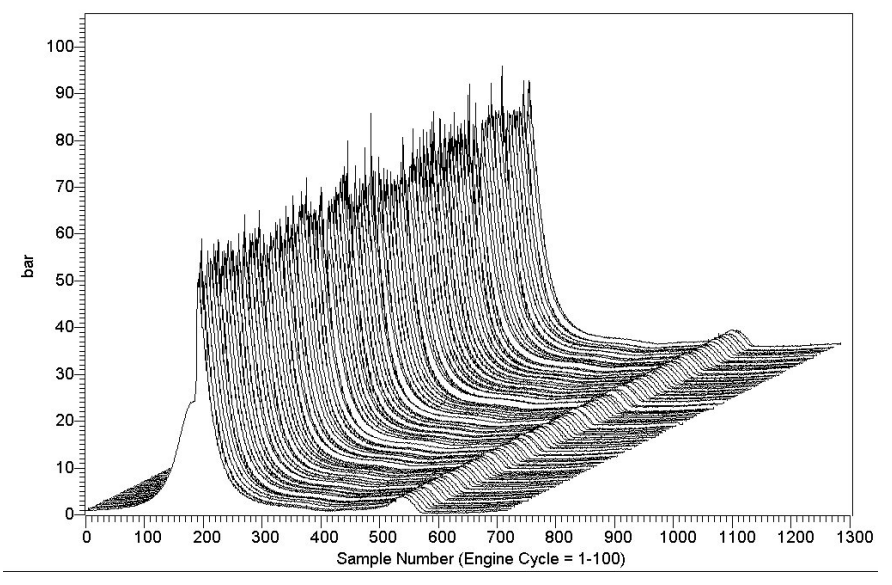

Figure 6 Pressure traces of CAl combustion using one exhaust valve

\section{Nitrogen and Air Substitution}

With the knowledge that CAI combustion can be initiated using a single exhaust valve with the same control strategy as that of double valves, we now have a platform to differentiate experimentally between the effects of true exhaust gas, and hot nitrogen and air substitutes on CAl combustion.

In order to substitute EGR with hot nitrogen or air while the other engine parameters remain unchanged, both exhaust valves were activated, but timed differently for two tasks during the test. Number one exhaust valve, which was connected to the nitrogen or air supply, was timed to draw in hot nitrogen into the combustion chamber during the intake process. Number two valve was connected to a conventional exhaust pipe and was timed to expel the exhaust gas from the cylinder during exhaust process. Figure 7 shows the valve timing. Therefore, combining the two valves together, a new valve control strategy, which is equivalent to the one 
used in the previous EGR test with a single valve, has been developed. Using this new strategy, we then could substitute EGR with hot nitrogen or hot air.

Since the aim of the experiments is to investigate the thermal and chemical effects of EGR separately, the thermal condition of the added gas should be maintained close to that of engine's EGR to isolate the chemical effect. This has been achieved by pre-conditioning the added gas. Two pre-condition parameters have been concerned here. One is the temperature. The added gas was pre-heated by two electric heaters. The first heater heated the gas to a temperature of $100^{\circ} \mathrm{C}$, and the second heater to further increase the temperature up to $>400^{\circ} \mathrm{C}$. The other parameter is the heat capacity of the added gas. It should be reasonably close to that of engine exhaust gas. This has been achieved by introducing water vapour into the added gas. The quantity of the water introduced into the substitute is about $15 \%$ by mass.
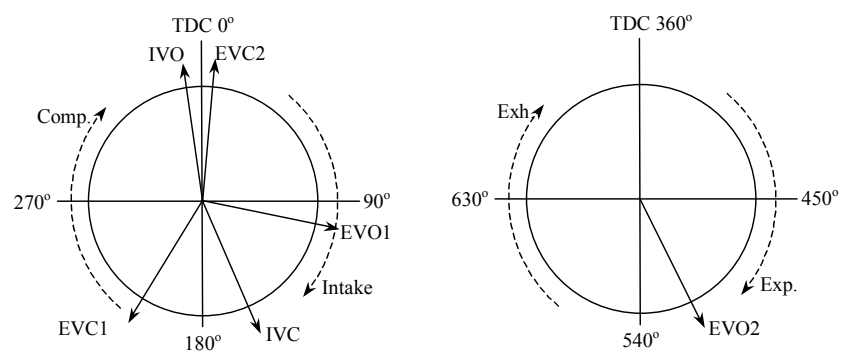

Figure 7 Valve timing for EGR substitution

The first set of substitution tests used hot nitrogen. During the test, the nitrogen is derived from a highpressure cylinder, then pre-conditioned by the two electric heaters to a temperature up to $400^{\circ} \mathrm{C}$ and fed into a cylinder at a pressure of approximately 0.4bar. The cylinder is then connected to one of the partitioned exhaust manifolds.

Figure 8 shows the measured cylinder pressure data with nitrogen introduction. The temperature of the nitrogen used was $400^{\circ} \mathrm{C}$. It can be seen that the pressure signals are rather similar to those presented in Figure 5 and 6 . However, there is a fundamental difference, which is the fact that during the test with nitrogen introduction, the combustion process can only be maintained under spark-ignition conditions. No CAI combustion has been achieved.

Figure 9 shows part of the cylinder pressure history during the experiment with nitrogen introduction: (a) combustion under spark assistance; (b) the period when spark plug being switched off and re-enabled; (c) the combustion after spark plug was re-enabled. From (b), it can be seen that the data is consisted of three parts. The first part is spark-assisted combustion following (a) with nitrogen introduction.
When the ignition was switched off, the combustion stopped. The engine simply began to slow down as shown in the middle part of the trace. In the third part, spark ignition was re-enabled, and the engine returned to 2000rpm. There is a distinct cylinder pressure spike as spark ignition is re-enabled. This large pressure spike arises from the combustion of the fuel entrained within the cylinder since the spark was disabled. Following this pressure peak, the engine again begins to run normally with nitrogen introduction but under spark ignition conditions as shown in (c).

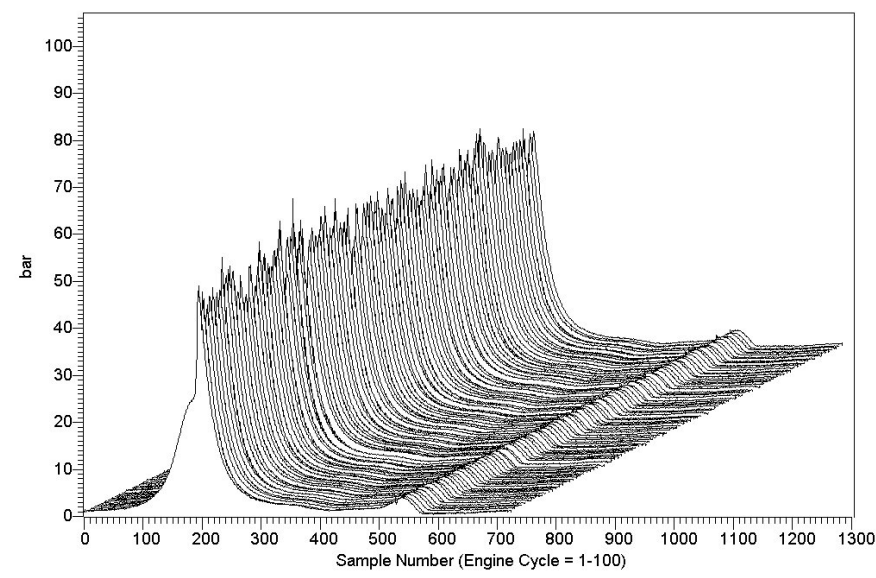

Figure 8 Pressure traces of $\mathrm{N}_{2}$ introduction, no CAI combustion achieved

As we have stated, nitrogen is stable and chemical species free. The experimental results clearly indicated that pre-conditioning nitrogen to a thermal condition equivalent to that of real EGR showed no sign of CAI combustion. For a $450 \mathrm{~cm}^{3}$ single cylinder engine with a 10.5:1 compression ratio, approximately $47 \mathrm{~cm}^{3}$ will remain as final clearance volume (or compression volume) containing trapped exhaust gas. If there are any chemical species which may be responsible for CAI combustion in the engine exhaust gas, their concentration will be negligibly low due to the relatively large quantity of nitrogen induction. It is clear that when a hot, basically free from active chemical species inert gas is substituted for hot real exhaust gas, although the thermal contribution is similar to that of EGR, CAI combustion cannot be sustained. This indicates that certain chemical species inside the engine exhaust gases do play a critical role in promoting or initiating CAI combustion.

Oxygen is part of the combustion reactants. From our work, we found that oxygen has the potential to improve fuel-oxidation reactions and therefore accelerate fuel auto-ignition reactions. Air contains about $21 \%$ oxygen. The thermal effect of air was judged by ramping the air temperature and the chemical effect is observed by monitoring whether CAl combustion can be achieved. The thermal capacity of the air was maintained close to that of EGR, again, by water introduction similar to that done during nitrogen substitution and about $15 \%$ of 
water was mixed with the hot air. The valve control strategies and other engine parameter remained the same as those for nitrogen introduction.

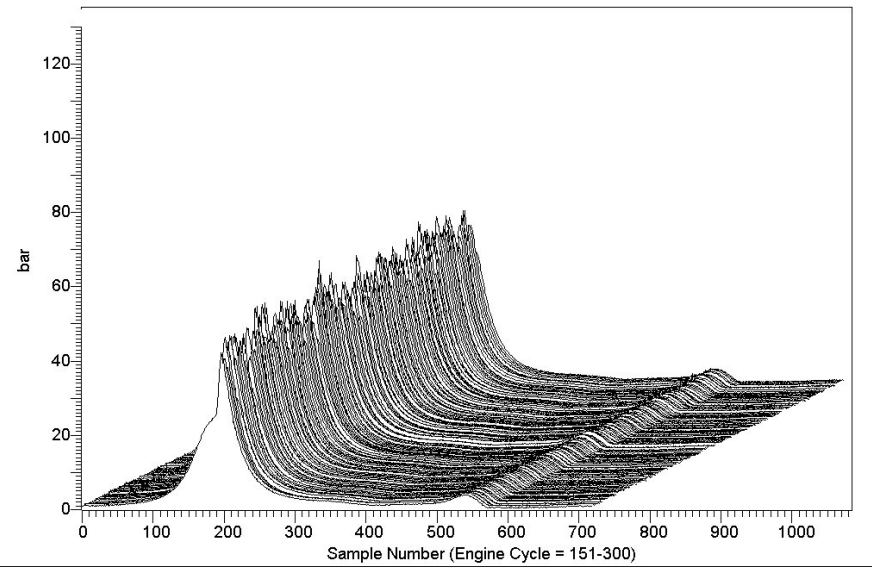

(a)

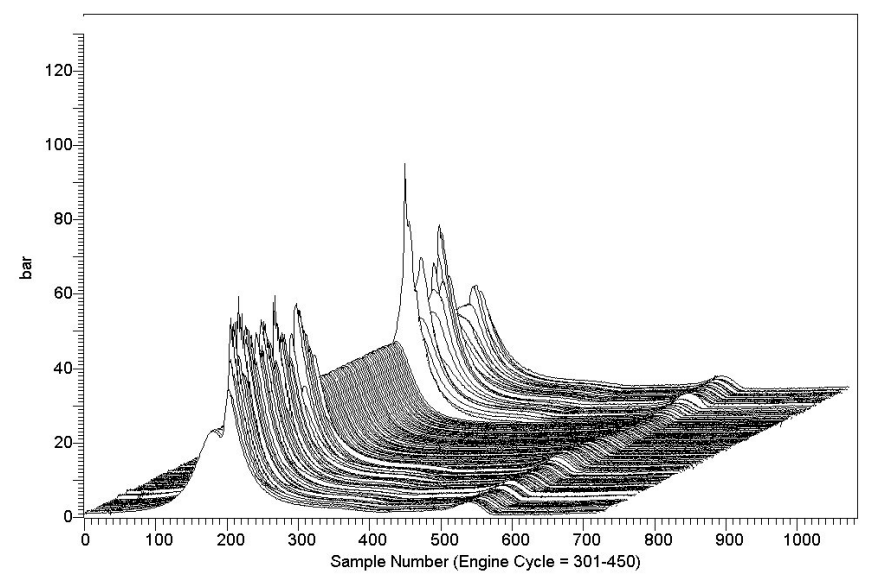

(b)

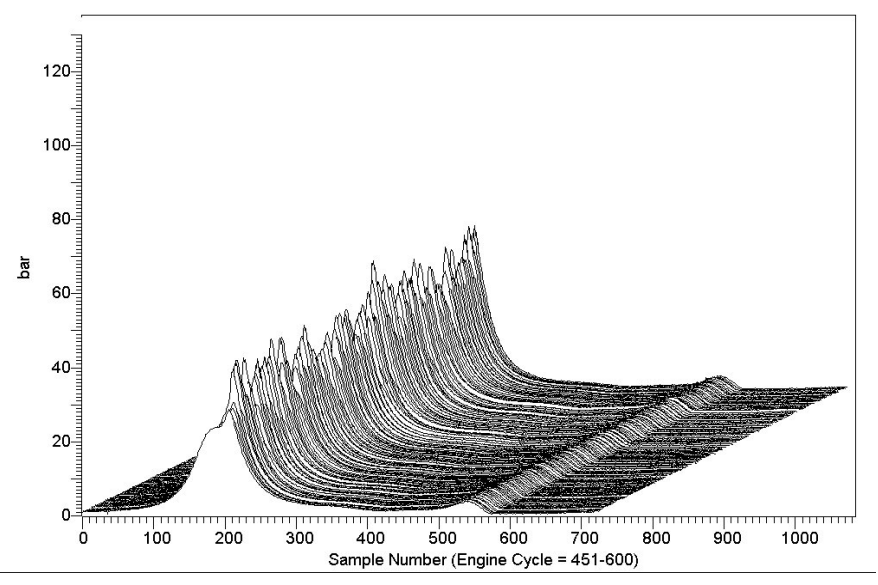

(c)

Figure 9 Pressure traces with $\mathrm{N}_{2}$ introduction with and without spark-assistance

The tests were started with (as per the nitrogen work) air at room temperature. The engine could not run without spark assistance. No CAI combustion can therefore be achieved. When the temperature was gradually increased to $120^{\circ} \mathrm{C}$, a dramatic effect was found. Combustion was sustained without the need for spark ignition, but became extremely violent. The usual form of controlled auto-ignition experienced with EGR introduction has been displaced by an uncontrollable violent auto-ignition normally associated with knock. When the temperature of the humid air is further increased to $130^{\circ} \mathrm{C}$, the auto-ignition became so violent that the test lasted only for a very limited period before the piston and valves were damaged as a consequence of such combustion. Figure 10 shows a data set collected with the introduction of hot humid air at $130^{\circ} \mathrm{C}$. It can be seen that the peak cylinder pressures were nearly doubled compared to those with EGR or nitrogen introduction.

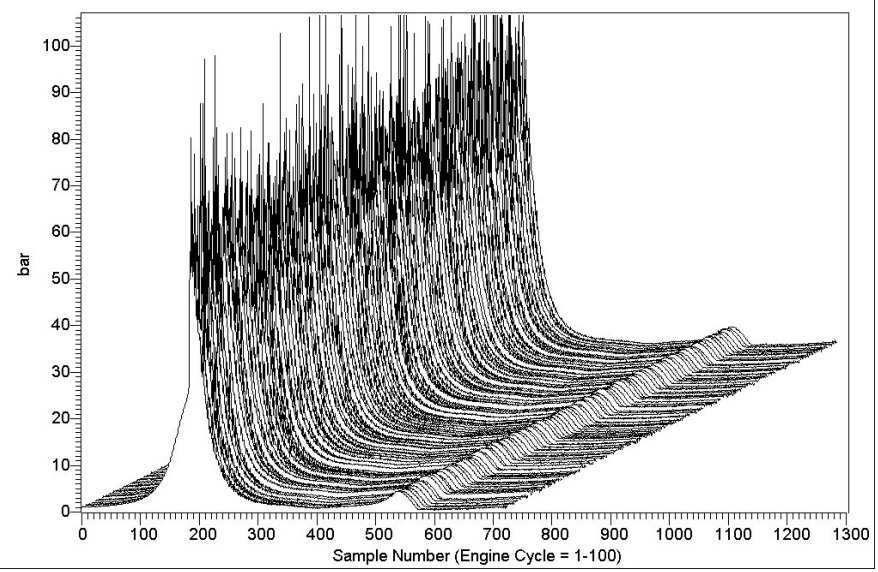

Figure 10 Pressure traces with air (at $130^{\circ} \mathrm{C}$ ) introduction

\section{DISCUSSION}

Figure 11 depicts typical pressure traces from the four reported tests: (a) CAI standard combustion with EGR drawn by both exhaust valves; (b) CAl combustion with EGR redrawn by one exhaust valve; (c) SI combustion with nitrogen introduction at $400^{\circ} \mathrm{C}$, no $\mathrm{CAl}$ combustion can be sustained; (d) uncontrollable form of auto-ignition combustion with hot air introduction at $130^{\circ} \mathrm{C}$. Table 2 summarises some key parameters obtained from these four tests.

For (a) and (b), it can be seen that although one of the exhaust valves was deactivated, CAl combustion could be sustained despite a few minor differences. These differences may be attributable to the flow restrictions caused by one valve being deactivated, or to the degree of homogeneity or heterogeneity of the fresh charge and internal EGR mixture. 


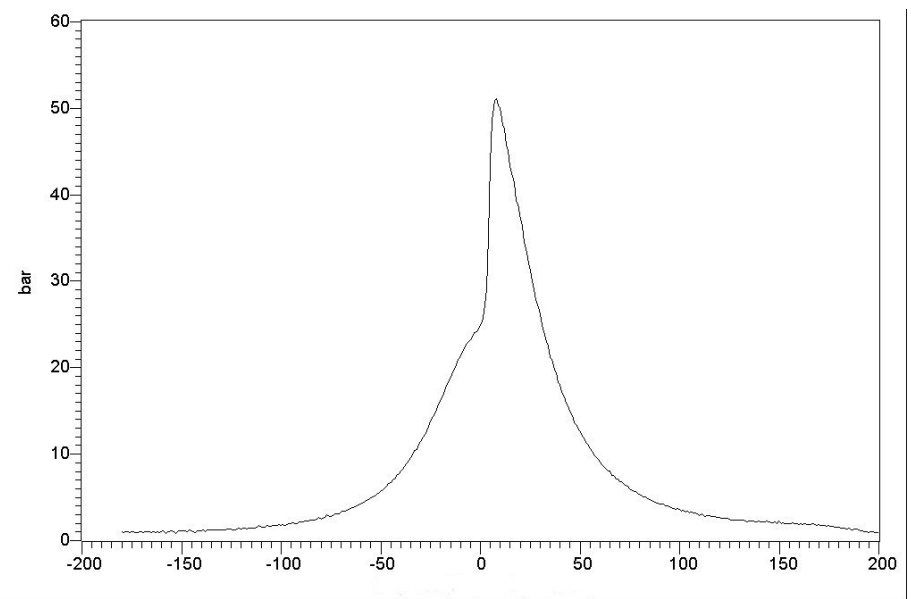

(a)

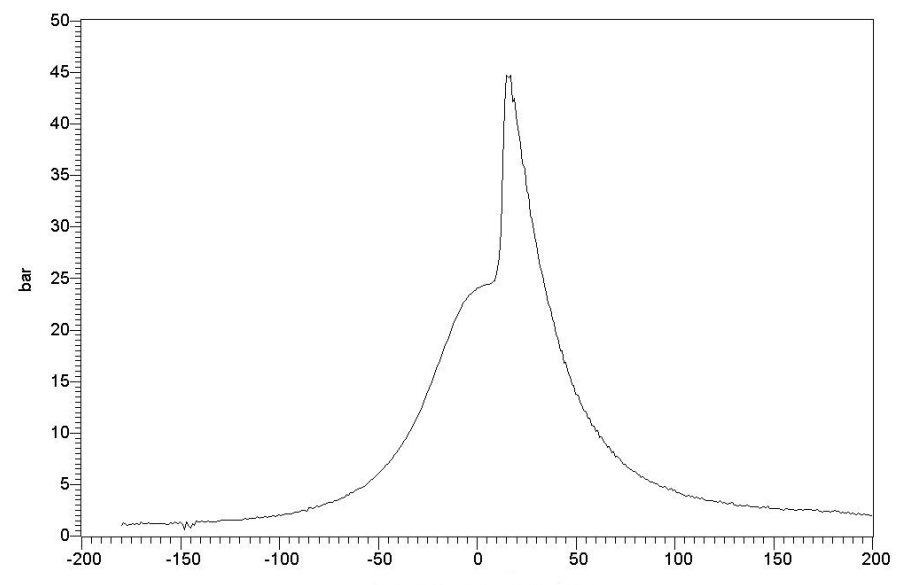

(c)

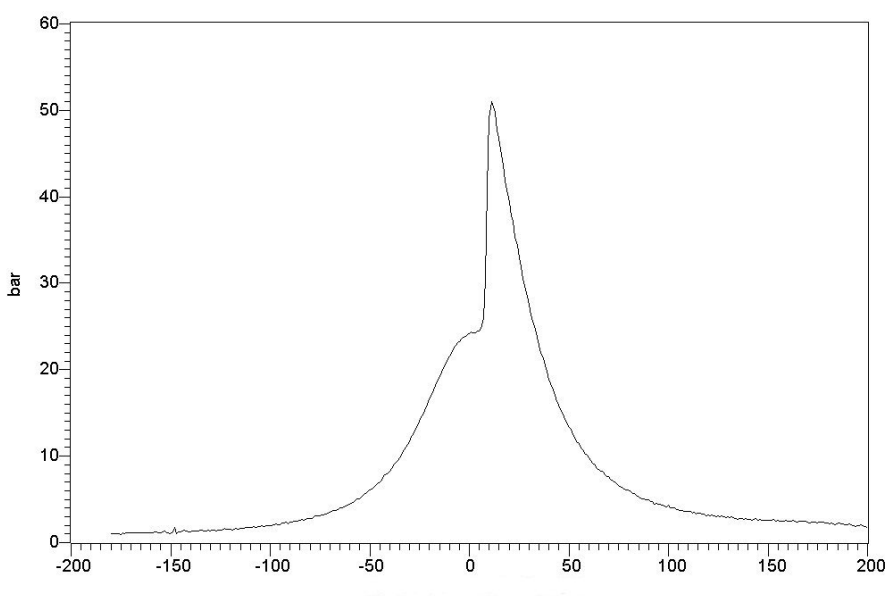

(b)

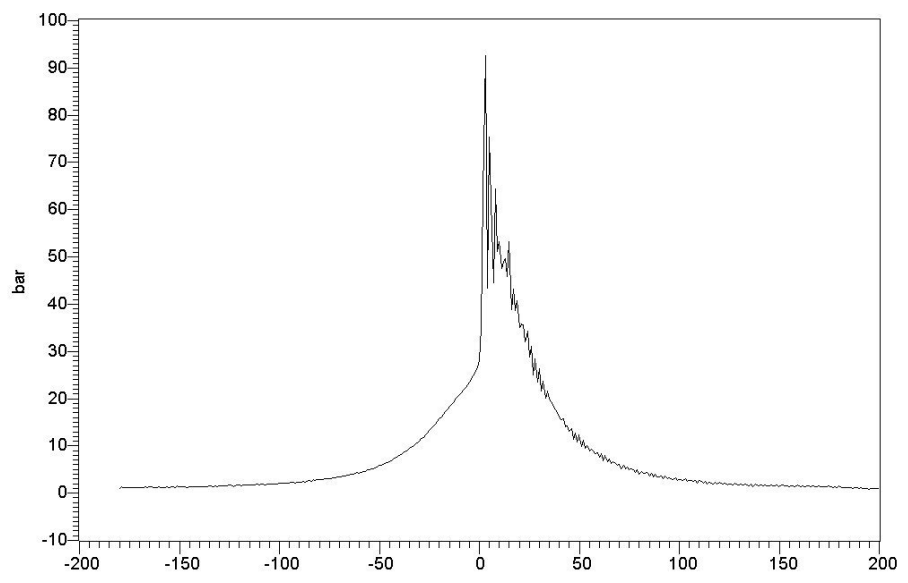

(d)

Figure 11 Typical pressure traces obtained from four experiments

Table 2 Combustion type and pressure data for the combustion event

\begin{tabular}{|l|c|c|c|c|}
\hline & $(\mathrm{a})$ & $(\mathrm{b})$ & $(\mathrm{c})$ & $(\mathrm{d})$ \\
\hline Angle of maximum pressure $\left(^{\circ}\right)$ & $8^{\circ}$ ATDC & $\begin{array}{c}12^{\circ} \\
\text { ATDC }\end{array}$ & $\begin{array}{c}16^{\circ} \\
\text { ATDC }\end{array}$ & $3^{\circ}$ ATDC \\
\hline Maximum pressure (bar) & 51 & 51 & 44.5 & 74 \\
\hline $\begin{array}{l}\text { Angle of maximum pressure rise } \\
\left({ }^{\circ}\right)\end{array}$ & $4^{\circ}$ ATDC & $9^{\circ}$ ATDC & $\begin{array}{c}13^{\circ} \\
\text { ATDC }\end{array}$ & $1^{\circ}$ ATDC \\
\hline Combustion type & CAI & CAl & SI & Al \\
\hline
\end{tabular}

To understand the chemical effect of EGR on CAI combustion, nitrogen at a similar thermal condition to that of EGR at $400^{\circ} \mathrm{C}$ has been used as a substitute. No CAl combustion could be sustained. The clear message is that EGR does have a strong chemical effect on CAI combustion. Comparing the cylinder pressure showed in (b) and (c) and the information given in Table 2, it can be seen that the ignition timing has been delayed by $4^{\circ}$ crank degrees and the maximum pressure rise time has increased by $45 \%$ due to nitrogen introduction.
Also, the peak pressure has been reduced by about $13 \%$. It is clear that although nitrogen can not ignite the combustion at the thermal condition equivalent to that of $E G R$, it can effectively smooth the combustion process due to its inert nature and dilution effect.

Oxygen is a reactant of combustion. With its introduction, no CAl combustion occurred till its temperature was ramped up to $120^{\circ} \mathrm{C}$. The reason behind such observation is that the thermal energy the air contained at low temperatures was not sufficiently 
high to help the engine's fuel charge to overcome its activation energy. There is a threshold temperature level with a certain quantity of air addition, which appears to be $120^{\circ} \mathrm{C}$ in this case. When the air temperature was raised higher than $120^{\circ} \mathrm{C}$, auto ignition starts, but is uncontrollably violent as shown in (d) and Table 2. It can be seen that the combustion ignition timing has been advanced by $9^{\circ}$ crank angle degrees and the peak cylinder pressure increase rate was about 13 times higher than that with EGR introduction. One clear message we can draw from the phenomenon is that oxygen advances auto ignition timing and accelerates the combustion reaction rate. However, despite its chemical contribution, its thermal contribution to combustion initiation appears to be essential.

Comparing the results of air and EGR introduction, it can be seen that air addition has converted the auto ignition combustion into an uncontrollable form normally associated with knock. EGR contains a large portion of nitrogen and a large number of reactive species include oxygen. Its chemical effect towards CAl combustion, therefore, comes from two sides. Reactive species make auto ignition easier and so the combustion can be initiated at relatively low temperature, while the nitrogen and other inert gases slow down the reaction rate and turn a potentially damaging violent auto ignition combustion into a controllable combustion.

\section{CONCLUSIONS}

Internal EGR has both thermal and chemical effects on CAl combustion. These have been studied in this research by substituting EGR with a pre-heated chemically inert gas (nitrogen), or a pre-heated chemically reactive gas (air), using a special engine fitted with an advanced electrohydraulic fully variable valve train system running with a new valve control strategy. It has been found that a higher chemical effect results in a lower requirement for the thermal effect and vice-versa.

This conclusion is reached because since nitrogen is chemically inert, its contribution towards combustion can be thermal only. Although nitrogen cannot initiate pure auto ignition (needing spark assistance and a temperature of at least $400^{\circ} \mathrm{C}$ ), it can delay combustion initiation and smooth the reaction rate.

Conversely oxygen is one of the combustion reactants, which has to be heated (as air) to $120^{\circ} \mathrm{C}$ to initiate unassisted auto ignition. Oxygen advances ignition timing, accelerates combustion to about 13 times that with EGR introduction, and turns the combustion into an uncontrollable form normally associated with knock.

EGR contains a high proportion of nitrogen and a large number of reactive species including oxygen. It therefore has both a thermal effect (due to its high temperature) and a chemical effect (due to its chemical content) on CAI combustion. The active species promote and initiate combustion, while the nitrogen and other inert gases slow down (or moderate) the reaction and turn a violent auto ignition event into a controllable form of combustion.

Finally, the work presented in this paper has shown that there is a strong dependence of CAI combustion on the chemical species EGR contains. However, in the context of this work, we have been unable to address the identification and the role of the specific chemical species in-cylinder. A new partial optical access single cylinder research engine is under commission, which will be coupled to a dedicated wide-band spectrometer and we, therefore, hope to address chemical speciation and combustion-role questions at the earliest opportunity.

\section{ACKNOWLEDGMENTS}

We would like to thank Ted Copland (Powertrain Technician) who ran the engine, and Dan Kemp, Dave Blundell and Jamie Turner (Powertrain Development) for their assistance with this work.

\section{REFERENCES}

1. S.Onishi, S.H.Jo, K.Shoda, P.D.Jo and S.Kato, Active Thermo Atmosphere Combustion (ATAC) - A New Combustion Process for Internal Combustion Engines, SAE 790501, 1979.

2. M.Noguchi, Y.Tanaka, T.Tanaka and Y.Takeuchi, A Study on Gasoline Engine Combustion by Observation of Intermediate Reactive Products During Combustion, SAE 790840, 1979.

3. Y.Ishibashi and Y.Tsishima, A New Generation of Engines for the Future, P.Duret (Editor) and Editions Technip, Paris 1993, p113-124.

4. P.Duret and S.Venturi, Automotive Calibration of the IAPAC Fluid Dynamically Controlled 2-Stroke Combustion Process, SAE960363.

5. E.Esterlingot, P.Guibert, J.Lavy and S.Raux, Thermodynamical and Optical Analyses of Controlled Auto Ignition Combustion in 2-Stroke Engines, SAE972098.

6. M.Kumada, H.Shimodaira, K.Yoshida, H.Shoji and A.Saima, Proc. 15th Int.Comb.Eng.Symp., Seoul Korea, July 13-16th , 1999, p395-400.

7. N.lida and T.Igarashi, Auto-ignition and Combustion of N-Butane and DNE/Air Mixtures in a Homogeneous Charge Compression Ignition Engine, SAE 2000-011832, 2000. 
8. Y.Ishibashi, Basic Understanding of Activated Radical Combustion and its 2-Stroke Engine Application and Benefits, SAE 2000-01-1836, 2000.

9. P.Duret, J-C.Dabadie, J.Lavy, J.Allen, D.Blundell, J.Oscarsson, G.Emanuelsson, M.Perotti, R.Kenny and G.Cunningham, The Air Assisted Direct Injection ELEVATE Automotive Engine Combustion System, SAE Fuels and Lubes, SAE FL487, 1999.

10. P.Duret, J-C.Dabadie, J.Lavy, J.Allen, D.Blundell, J.Oscarsson, G.Emanuelsson, M.Perotti, R.Kenny and G.Cunningham, SAE Fuels and Lubes, Innovative Design and Simulation Study of the ELEVATE Automotive Engine Project, SAE Congress, Paris, 2000.

11. P.M.Najt and D.E.Foster, Compression Ignited Homogeneous Charge Combustion, SAE 830264, 1983.

12. R.H.Thring, Homogeneous Charge Compression Ignition (HCCl) Engines, SAE 892068, 1989.

13. M.Stockinger, H.Schapertons and P.Kuhlman, MTZ 53(1992)2, p80-85 (in German).

14. T.Aoyama, Y.Hattori, J.Mzuta and Y.Sato, An Experimental Study on Premixed Charge Compression Ignition Gasoline Engine, SAE 960081, 1996.

15. Lavy et al. (14 authors), Innovative Ultra Low NOx Controlled Auto Ignition Combustion Process for Gasoline Engines: the 4-SPACE Project, SAE 2000-01$1837,2000$.

16. D.Law, J.Allen, D.Kemp and P.Williams, 4-Stroke Controlled Auto Ignition Investigations Using a Single Cylinder Engine with Lotus Active Valve Train (AVT), Proceedings of the 21st Century Emissions Technology Conference, Paper C588/006/2000, I.Mech.E., London, 4-6th December 2000,

17. D.Law, D.Kemp, J.Allen, G.Kirkpatrick and T.Copland, Controlled Combustion in an IC-Engine with a Fully Variable Valve Train, SAE 2001-01-0251, 2001.

18. A.Oakley, H.Zhao, N.Ladommatos and T.Ma, Experimental Studies on Controlled Auto-Ignition (CAI) Combustion of Gasoline in a 4-Stroke Engine, SAE 2001-01-1030, 2001

19. R.Chen and N.Milovannovic, A review of Experimental and Simulation Studies on Controlled Auto-Ignition Combustion, SAE 2001-01-1890, 2001.

20. Jeff Allen and Don Law, Advanced Combustion Using a Lotus Active Valve Train: Internal Exhaust Gas Recirculation Promoted Auto-Ignition, Proceedings of the IFP International Congress, A New Generation of
Engine Combustion Processes for the Future, 26-27th November 2001, IFP, Paris.

21. J.Allen, D.Law and D.Kemp, CAI International Patent Filing, 9930380.2, 1999.

22. D.Law, J.Allen, D.Kemp and P.Williams, 4-Stroke Controlled Auto Ignition Investigations Using a Single Cylinder Engine with Lotus Active Valve Train (AVT), Proceedings of the 21st Century Emissions Technology Conference, I.Mech.E., London, 4-6th December 2000.

23. M.Noguchi, Y.Tanaka, T.Tanaka and Y. Takeuchi, A study on Gasolne Engine Combustion by Observation of Intermediate Reactive Products During Combustion, SAE 790840, 1979.

24. N.lida, Combustion Analysis of Methanol-Fueled Active Thermo Atmosphere Combustion (ATAC) Engine Using Spectroscopic Observation, SAE 940684, 1996.

25. H.Ando, Combustion Control Technologies for Gasoline Engines, I.Mech.E. Conf., Paper S433/001/96, 1996.

26. M.Kumada, H.Shimodaira, K.Yoshida, H.Shoji and A.Saima, A Study $\mathrm{n}$ Ion Current and $\mathrm{OH}$ Radical Luminsecence Behaviour in the Progression from Normal Combustion to Knocking in a 2-Stroke Engine, Proc. 15th Int.Comb.Symp.(Int.), Seoul, Korea, July 1315, p395-400, 1999.

27. A.Hultqvist, M.Christensen, B.Johansson, A.Franke, M.Richter and M.Alden, A Study of the Homogeneous Charge Compression Ignition Combustion Process by Chemiluminescence Imaging, SAE 1999-01-3680, 1999.

28. F.E.Corcione, M.Costa, B.M.Vaglieco and A.De Maio, The Role of Radical Species in Diesel Engine Auto-Ignition Detection, SAE 2001-01-1003, 2001.

29. J.Zheng, W.Yang, D.L.Miller and N.P.Cernansky, Prediction of Pre-Ignition Reactivity and Ignition Delay for HCCI Using a Reduced Chemical Kinetic Model, SAE 2001-01-1025, 2001.

30. K.Tanaka, H.Endo, A.Imamichi, Y.Oda, Y.Takeda and T.Shimada, Study of $\mathrm{HCCl}$ Using a Rapid Compression Machine, SAE 2001-01-1033, 2001.

31. H.Ando and K.Kuwahara, A Keynote on Future Combustion Engines, SAE 2001-01-0248, 2001.

32 R.Chen and N.Milovanovic, A Computational Study into the Effect of Exhaust gas Recycling on Homogeneous Charge Compression Ignition Combustion in Internal Combustion Engines Fuelled with Methane, International Journal of Thermal Science, in press, 2001. 
Licensed to Loughborough University

Licensed from the SAE Digital Library Copyright 2011 SAE International

E-mailing, copying and internet posting are prohibited

Downloaded Wednesday, May 25, 2011 4:17:08 AM 